See discussions, stats, and author profiles for this publication at: https://www.researchgate.net/publication/319052482

\title{
Genomic regions and pathways associated with resistance to gastrointestinal parasites in tropical sheep breed.
}

Conference Paper in Journal of Animal Science · August 2017

Dol: $10.2527 /$ asasann.2017.216

\section{CITATIONS}

13 authors, including:

Mariana Berton

São Paulo State University

51 PUBLICATIONS 95 CITATIONS

SEE PROFILE

(8) Elisa Peripolli

São Paulo State University

49 PUBLICATIONS 70 CITATIONS

SEE PROFILE
READS

22

Rafael Medeiros de Oliveira Silva

University of Georgia

54 PUBLICATIONS 172 CITATIONS

SEE PROFILE

Nedenia B Stafuzza

Instituto de Zootecnia

171 PUBLICATIONS 268 CITATIONS

SEE PROFILE

Some of the authors of this publication are also working on these related projects:

Study of multicollinearity in composite beef cattle View project

PARÂMETROS GENÉTICOS RELACIONADOS À MARCHA E À CONFORMAÇÃO DE EQUINOS DAS RAÇAS MANGALARGA E CAMPOLINA View PrOject 
216 Genomic regions and pathways associated with resistance to gastrointestinal parasites in tropical sheep breed. M. P. Berton ${ }^{*}$, R. M. D. O. Silva ${ }^{1}$, E. Peripolli ${ }^{1}$, N. B. Stafuzza ${ }^{2}$, J. Fernández ${ }^{3}$, M. Saura ${ }^{3}$, B. Villanueva ${ }^{3}$, M. A. Toro ${ }^{4}$, G. Banchero ${ }^{5}$, P. S. Oliveira ${ }^{6}$, J. P. Eler ${ }^{7}$, F. Baldi ${ }^{1}$, and

J. B. S. Ferraz ${ }^{7},{ }^{1}$ Department of Animal Science, School of Agricultural and Veterinarian Sciences, Sao Paulo State University, Jaboticabal, Brazil, ${ }^{2}$ Departamento de Ciências Exatas, Faculdade de Ciências Agrárias e Veterinárias, Universidade Estadual Paulista, Jaboticabal, Brazil, ${ }^{3}$ Instituto Nacional de Investigación y Tecnología Agraria y Alimentaria, Madrid, Spain, ${ }^{4}$ Animal Production Department, Universidad Politecnica de Madrid, Madrid, Spain, ${ }^{5}$ INIA, Colonia, Uruguay, ${ }^{6}$ University of Sao Paulo, Pirassununga, Brazil, ${ }^{7} N A P-G M A B T /$ FZEA/University of Sao Paulo, Pirassununga, Brazil.

The aim of this study was to estimate variance components and to identify genomic regions and pathways associated with resistance to gastrointestinal parasites, particularly Haemonchus contortus, in Santa Inês sheep, a Brazilian breed adapted to tropical climate. The degree of anemia assessed by the FAMACHA card (FAM) and the egg counts per gram of feces (EPG) were evaluated to verify the resistance to gastrointestinal parasites. A total of 576 animals were genotyped using 12,785 SNPs of the Ovine SNP12k BeadChip (Illumina, Inc.). The variance components were estimated using a single trait model by single step genomic BLUP (ssGBLUP) procedure. The overall LD mean between marker pairs measured by $r^{2}$ was 0.23 . Heritability estimates were low for EPG (0.11) and high for FAM (0.35). A total of 22 and 21 important windows for EPG and FAM traits were identified. The results of the enriched genes and functional grouping analyses showed that genes associated with FAM and OPG are involved in functions related to the body's immune and defense response. The CCL28 gene located in OAR16 identified both for EPG and FAM acts as a chemotactic for CD4 and CD8 inactive T cells. The metabolic pathway involved in the CCL28 gene and in other genes associated with EPG and FAM, which are related to immunoglobulin synthesis in the intestine. The high heritability observed for FAM suggests that good genetic progress should be possible in selective breeding programs for Santa Inês sheep besides the fact that the FAM is the most precise method to identify an infection by Haemonchus when compared to EPG. This study reported for the first time estimates of linkage disequilibrium between markers and genetic parameters for traits related to gastrointestinal parasite resistance in the Santa Inês sheep breed.

Key Words: GWAS, linkage disequilibrium, parasite resistance

doi:10.2527/asasann.2017.216

\section{COMPANION ANIMALS}

\section{Outdated perceptions influence the acquisition of pet dogs in the United States and quietly reshape the dog market place. P. Strand ${ }^{* 1}$, J. New ${ }^{2}$, F. O. Smith ${ }^{3}$, and B. Reichman ${ }^{4},{ }^{1}$ National Animal Interest Alliance, Portland, OR, ${ }^{2}$ University of Tennessee, Knoxville, ${ }^{3}$ Orthopedic Foundation for Animals, Burnsville, MN, ${ }^{4}$ National Animal Interest Alliance, Port Murray, NJ.}

Introduction: As of 2015, 44\% of American households had at least one dog, with recent surveys indicating 70-80 million in U.S. homes and nearly 7 million dogs needed annually just to replace the ones that die each year. ${ }^{1,2}$ Given the popularity of dogs in the U.S. and the economic activity surrounding their acquisition, it is surprising how little notice has been paid to the changing sources of dogs available to the public today. The objective of this study was to examine consumer perceptions and preferences regarding U.S. dog acquisition and to consider how current trends and perceptions impact the availability, type, and quality of pet dogs in the future. Methods: An online survey was administered to 1000 respondents. The survey asked questions about current dog ownership, future pet dog acquisition plans, consumer dog preferences (e.g. size, breed), and consumer beliefs regarding dog overpopulation. Results: About half (49.3\%) of respondents currently owned at least one dog and $38 \%$ of respondents anticipated acquiring a new dog within the next 5 years. The two most important characteristics impacting this decision were the dog's predictable size (42.8\%) and purebred status (41.2\%). When asked whether the U.S. had a surplus of dogs based on their perception of the number of dogs entering animal shelters, $63.7 \%$ of respondents believed there was a surplus, and of these, $58.8 \%$ thought that the domestic surplus of dogs was getting worse. Most respondents $(66.6 \%)$ were not aware that some animal shelters import dogs from other states or countries. While $43.7 \%$ of respondents were supportive of importation of dogs from other states, only $16 \%$ were supportive of importing dogs from other countries. Discussion: The study confirmed high levels of dog ownership and support for future dog acquisitions and identified consumer preferences for specific types of dogs. The study also revealed that prospective dog owners were uncertain about the type of dogs available in animal shelters as well as the perception of continued U.S. dog overpopulation. The degree to which these perceptions affect the marketplace is a major concern. While there will always be overseas street dogs available for importation into the U.S., one concern of the study regards the shrinkage of purebred dog segment in response to a belief in domestic overpopulation. References: ${ }^{1}$ APPA National Pet Owners Survey, 2015-2016, p. 64-65. ' U.S. Pet Ownership \& Demographics Sourcebook (2012), www.avma.org/KB/Resources/Statistics/ 